\title{
Modelagem de crescimento de bovinos submetidos a diferentes tratamentos
}

\author{
Altemir Bortuli Junior* \\ Licenciatura em Matemática, Universidade Estadual do Centro-Oeste, UNICENTRO. \\ 85040-080, Guarapuava, PR \\ E-mail: altemirbortulijunior@hotmail.com \\ Maria José de Paula Castanho \\ Thiago Formehl \\ Universidade Estadual do Centro-Oeste - Departamento de Matemática \\ 85040-080, Guarapuava, PR \\ E-mail: zeza@unicentro.br thiagoformehl@hotmail.com
}

\section{RESUMO}

Modelos matemáticos descritos por equações diferenciais não lineares têm sido utilizados para descrever níveis de crescimento em animais. Dentre eles, o modelo de Von Bertalanffy foi aplicado em curvas de crescimento de diversas espécimes, apresentando qualidade elevada de ajuste e estimativas condizentes com a realidade, quando comparado à outras curvas de crescimento [2,3,5].

O objetivo deste trabalho é verificar se há diferença de crescimento em bovinos da raça Canchim, submetidos a diferentes tratamentos, usando o modelo de Von Bertalanffy.

Os dados foram obtidos experimentalmente no Núcleo de Produção Animal (NUPRAN) do Setor de Ciências Agrárias e Ambientais da Universidade Estadual do Centro-Oeste (UNICENTRO). O experimento foi realizado com 24 animais da raça Canchim, confinados em 12 baias e com idade média de 10 meses. Foram utilizados quatro tratamentos para alimentação desses animais: Tratamento 1, ração RAB-Confinamento associado a silagem de milho com $25 \%$ de matéria seca; Tratamento 2, ração RAB-Confinamento associado a silagem de milho com 32\% de matéria seca; Tratamento 3, ração RAB-E-15 associado com silagem de milho com $25 \%$ de matéria seca e Tratamento 4, ração RAB-E-15 associado com 32\% de matéria seca.

O modelo de Von Bertalanffy [1], modificado por West [6], foi utilizado para descrever os quatro tratamentos:

$$
\left\{\begin{array}{l}
\frac{d P}{d t}=\alpha P^{\frac{\pi}{4}}-\beta P \\
P(0)=P_{0}
\end{array}\right.
$$

em que: $\mathrm{P}=\mathrm{P}(\mathrm{t})$ é a massa do animal em função do tempo $\mathrm{t}, P_{0}$ é a massa inicial, $\alpha$ é a constante de anabolismo (representando a taxa de síntese de massa por unidade de superfície animal) e $\beta$ é a constante de catabolismo (que representa a taxa de diminuição da massa por unidade de massa)[7]. O termo $P^{\frac{\pi}{4}}$ é proveniente da relação alométrica do peso com a área corporal para mamíferos. Este parâmetro foi utilizado por Oliveira [3] que obteve bons resultados em seu trabalho com suínos de corte.

A solução do modelo é dada por:

$$
\mathrm{P}(\mathrm{t})=P_{\infty}\left\{1+\left[\left(\frac{P_{0}}{P_{\infty}}\right)^{1 / 4}-1\right] e^{-\frac{\beta \mathrm{t}}{4}}\right\}^{4},
$$

em que $P_{\infty}$ é o peso máximo esperado para os animais, satisfazendo a relação $P_{\infty}=\left(\frac{\alpha}{\beta}\right)^{4}$. O parâmetro $P_{0}$ representa o peso médio inicial.

Os modelos que descrevem os tratamentos são os seguintes, representados na Figura1:

* Bolsista de Iniciação Científica Fundação Araucária 
Tratamento 1: $\quad P_{1}(t)=746\left(1-0,1843 e^{-0,00721 t}\right)^{4}$

Tratamento 2: $P_{2}(t)=701,7\left(1-0,1646 e^{-0,00837 t}\right)^{4}$

Tratamento 3: $P_{3}(t)=811,2\left(1-0,1990 e^{-0,00576 t}\right)^{4}$

Tratamento 4: $P_{4}(t)=650\left(1-0,1524 e^{-0,00806 t}\right)^{4}$

Figura 1: Modelo de Von Bertalanffy para descrever o peso de bovinos da raça Canchim, submetidos a quatro tratamentos.
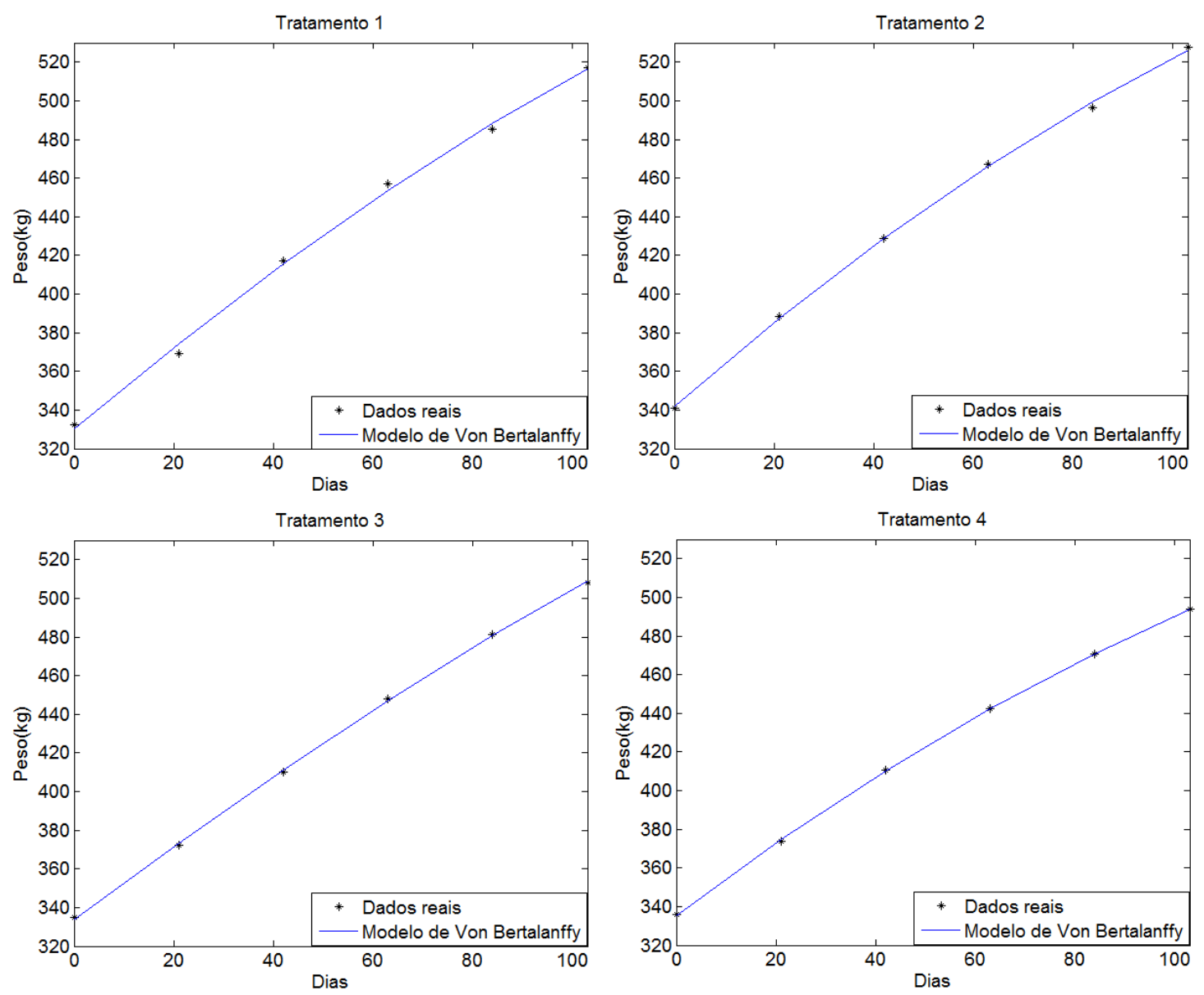

Para verificar se há diferenças significativas entre os tratamentos, serão testadas as seguintes hipóteses:

(a) $H_{0}$ : os modelos que descrevem os tratamentos são idênticos, isto é, um modelo comum pode ser usado para descrevê-los; $H_{a}$ : os modelos diferem entre si; e

(b) $H_{0}$ : um determinado subconjunto de parâmetros é igual em dois tratamentos; $H_{a}$ : os parâmetros diferem entre os tratamentos.

Para isso, é utilizado o método descrito por Regazzi [4] que usa o teste da razão de verossimilhança.

Considerando o modelo de Von Bertalanffy com a seguinte parametrização:

$P_{i j}=a_{i}\left(1-b_{i} e^{-c_{i} t_{i j}}\right)^{4}$,

com $j=1, \ldots, n_{i}$ ( $n$ é o número total de observações de cada tratamento $i$ ) $i=1,2 \quad \mathrm{e}$ $a_{i}, b_{i}, c_{i}>0$.

* Bolsista de Iniciação Científica Fundação Araucária 
Calcula-se $S Q R_{\Omega}$ a soma de quadrados residual para o modelo calculado e $S Q R_{\omega}$ para o modelo sujeito à restrição dada por $H_{0}$ e obtém-se a estatística do teste que tem aproximadamente distribuição de qui-quadrado [4]:

$$
\chi_{\text {calculado }}^{2}=-n \ln \left(\frac{S Q R_{n}}{S Q R_{\omega}}\right) \text {. }
$$

Para o desenvolvimento deste trabalho foi utilizado o software Matlab® para construir os modelos e o SAS® para compará-los.

O trabalho está em desenvolvimento, portanto, ainda não há resultados da comparação. Até o momento podemos concluir que o modelo de Von Bertalanffy descreve bem os quatro tratamentos.

Palavras-chave: Modelo de Von Bertalanffy, bovinos de corte, verossimilhança.

\section{Referências}

[1] R. C. Bassanezi, "Ensino-Aprendizagem com modelagem matemática: Uma nova estratégia", Contexto, São Paulo, 2002.

[2] T. Formehl, M.J.P. Castanho, M. Newmann, Modelos matemáticos para descrever o aumento de peso em gado de corte, em "XII ERMAC - Encontro Regional de Matemática Aplicada e Computacional”, Foz do Iguaçu, PR (2008).

[3] L.Oliveira, , A. J. V.Brandão, e R. C. Bassanezi, Modelo de Von Bertlanffy generalizado aplicado ao crescimento de suínos de corte, Biomatemática, vol. 17, pp.101-109, (2007).

[4] A. J. Regazzi, Teste para verificar a igualdade de parâmetros e a identidade de modelos de regressão não-linear, Ceres, vol. 50, pp. 9-26,( 2003).

[5] J.Scapim, R. C. Bassanezi, Modelo de Von Bertalanffy generalizado aplicado a curvas de crescimento animal, Biomatemática, vol. 18, pp.1-14, (2008).

[6] G. B. West, W. H.Woodruff, J. H. Brown, Allometric scaling of metabolic rate from molecules and mitochondria to cells and mammals, Proceedings of the National Academy of Sciences of the United States of America, vol. 99, pp.2473-2478, (2002). 